\title{
The space of all proportional voting systems and the most majoritarian among them
}

\author{
Pietro Speroni di Fenizio ${ }^{1}$ - Daniele A. Gewurz ${ }^{2}$
}

Received: 10 July 2017 / Accepted: 30 November 2018 / Published online: 12 December 2018

(C) The Author(s) 2018

\begin{abstract}
We present an alternative voting system that aims at bridging the gap between proportional representative systems and majoritarian electoral systems. The system lets people vote for multiple party-lists, but then assigns each ballot paper to a single party. This opens a whole range of possible parliaments, all proportionally representative. We show theoretically that this space is convex. Then among the possible parliaments we present an algorithm to produce the most majoritarian result. We then test the system and compare the results with a pure proportional and a majoritarian voting system showing how the results are comparable with the majoritarian system. Then we simulate the system and show how it tends to produce parties of exponentially decreasing size with always a first, major party with about half of the seats. Finally we describe how the system can be used in the context of a parliament made up of two separate houses.
\end{abstract}

\section{Introduction}

One of the main difficulties in choosing an electoral systems is how to approach the dichotomy between governability and representativeness. The general consensus is that it is impossible to have a system that is both proportionally representative and that assures a sufficient concentration of power in few parties to give them the possibility to efficiently govern a country. Such dichotomy will then be reflected in who supports what type of electoral system, with people voting for small parties supporting a proportional system (which would give them the possibility of having a presence in parliament), while people voting for bigger parties supporting a majoritarian one

$凶$ Daniele A. Gewurz gewurz@gmail.com

Pietro Speroni di Fenizio pietros@gmail.com

1 Università degli Studi G. D’Annunzio di Chieti Pescara, viale Pindaro 42, Pescara, Italy

2 Via Marcantonio Bragadin 20, 00136 Rome, Italy 
(which would give them the possibility to govern). Often the result is a compromise that does not assure neither enough representativeness nor governability. These issues are studied in depth in texts such as Reynolds et al. (2005) and Sartori (1994).

We are going to show in this paper that this is actually a false dichotomy, and it is possible to generate a system that is a faithful representation of what the electorate desires, and at the same time affords the winning parties enough seats to govern a country.

Note that we shall consider here a voting system where parties are elected, and representatives as members of parties, rather than a system that directly elects representatives. Electoral systems generally fall within three broad categories: single-winner voting systems, multiwinner voting systems, or party-list systems. In a single-winner voting system only a single candidate is elected. In a multiwinner voting system multiple candidates are elected. Party-list systems are somehow different, as they do not directly elect candidates, but assign certain percentages of the seats of a parliament to a party; then the particular candidates who will fill those seats will be chosen within those parties. The three kinds of systems are different not just in procedure, but in mathematical qualities as well. And while single-winner voting systems have been thoroughly investigated using axiomatic methods in the last 70 years (in the wake of Arrow's theorem 1950), more recently there has been an attention towards multiwinner voting systems. Systems where parties are directly attributed a percentage of the parliament seem not to have been studied with such a careful mathematical approach. ${ }^{1}$

As will be seen, the system that we are presenting has an underlying spirit in common with single transferable vote (STV): voters are asked to express all the preferences they desire, rather than just one, and it is the machinery of the system that extracts a single preference from each ballot. On the other hand, the setting of STV is completely different from the system described here. The former involves choosing among single candidates (to form a multi-seat board), rather than among parties (to which seats are to be assigned). The STV's outcome is, for each candidate, an in-or-out result, while in the system presented here the outcome is, for each party, a number of elected representatives. From a technical point of view, moreover, the main difference is that in an STV election the voters select the candidates ranking them, and the candidates compete against each other. The fact that a single party may have a majority of the parliament is then a side effect of the fact that STV is usually applied to small constituencies. In our system we aim at designing a system where, even when constituencies are nationwide, the result is majoritarian.

We shall start by defining under what conditions we shall say that a voting system is proportionally representative and, in contrast, what kind of voting systems would fall short of such definition. Then we define our voting procedure and then show that by slightly changing it, we can find many different parliaments, all representative of the electorate's wishes. At that point we will have moved our problem from a single solution problem to a problem that admits several solutions. In fact, we will show that the space of representative parliaments is not just a subset of the space of possible parliaments but a convex subset of the simplex of all possible parliaments. Then, it

\footnotetext{
1 For instance, the excellent mathematical investigation of multiwinner voting (Faliszewski et al. 2017) does not dwell on this kind of systems, while the reference text Electoral System Design: The New International IDEA Handbook (Reynolds et al. 2005) does not dwell on their mathematical aspects.
} 
will be possible to design a voting system that, while assuring representativeness, also satisfies other criteria, among which having some larger parties. Thus, this voting system is a possible definitive solution out of this conundrum.

We tested the system using a simulated scenario made up of 20 parties with 5000 voters and we present the results of this as well. We observed that the resulting sizes of the parties decrease following an exponential law which is independent on the number of voters or on the number of parties. Thus it is always the case that one big party is created followed by all the other parties, decreasing in size following roughly the same proportion.

We also tested the system by letting two groups of university students vote on the main parties present at the time in the Italian parliament. Then we analysed the resulting ballot papers using this system, as well as using the pure proportional system and the then present Italian system (known as Italicum, ${ }^{2}$ a two-round system with a majority bonus and an election threshold.). The result of our system is very similar to the Italicum system, with the added benefit that each elected representative can point to a set of ballot papers that elected him, something which cannot be done in the Italicum system, making it a proportionally representative system.

\section{Definition of proportional representativeness}

\section{We shall call a system proportionally representative if:}

1. each MP has been elected by groups of voters of more or less equivalent size;

2. each voter ballot paper helped to elect a member of parliament he voted for, unless he is part of a group of voters too small to elect even a single representative.

In other words, each group of people who is sufficiently large to have at least one representative and sufficiently homogeneous to agree on which party to vote will be represented. At the same time, each elected representative will represent about the same proportion of population.

From this definition the only traditional proportionally representative system would be a unique national constituency proportional system. That is, a system where each party presents a single list, and the parliament is produced by electing people from those lists assigning a number of seats directly proportional to the votes received.

This kind of system is rarely chosen, as the resulting parliament is often deemed "too proportional", with several small parties and thus unable to govern the country.

This is very well expressed by Florin Fesnic (Fesnic 2008): "This illustrates the inherent tension that exists in proportional representation systems. If the system is too proportional, it can lead to fragmentation and instability. If the system is made less proportional, either through low district magnitude or through a high threshold, it starts resembling a winner-take-all system, and by doing so defeats the very purpose of proportional representation."

Let us recall that there are several strategies that are often used to make sure that the resulting system is not too fragmented.

\footnotetext{
2 As described in Law nr. 52, 6 May 2015, published in Gazzetta Ufficiale on 8 May 2015: www. gazzettaufficiale.it/eli/id/2015/05/08/15G00066/sg.
} 
Majority bonus This strategy consists in giving to the party with the relative majority extra seats in the parliament, possibly even letting it reach the absolute majority. Of course this system cannot be used inside a proportionally representative system, as those seats break the fixed ratio between the elected members and their voters. The extra elected people who gain access to the parliament will not be representative of any specific block of voters. And if we were to divide the voters of the first party into smaller blocks this would violate the assumption that each elected candidate should represents blocks of people of the same size.

Election threshold This strategy consists in requiring that the only parties allowed to seat in the parliament are those having at least a certain percentage of votes. In a sense it is inevitable that there is always a threshold, as it is not possible to elect less than one representative. Thus any block of people who chose a party that would elect less than one representative would be automatically excluded from the parliament. The election threshold raises this requirement, thus making the system not representative for all those people who vote smaller parties and not proportional for those who voted greater parties. Again, this is a strategy that prevents a system from being representative.

Single-member constituency election This kind of systems elect a single representative for each local area. This was due historically to the difficulty in organising an election distributed through several geographical areas, so each place would elect its own representative. The problem with this is similar to the problem with the election threshold, but repeated for each constituency. In every constituency only the majority party will be able to send a representative to the parliament. As such any party which is distributed throughout the whole nation, but it is not majoritarian anywhere, will be excluded. This system keeps out of the parliament any except the biggest parties. It is, as such, among the least proportionally representative systems. A similar problem, although in a lesser form, occurs for systems with small constituencies. And the bigger a constituency is, the more representative the system will be.

In this paper we will present a system that does not uses any election threshold, uses a single nationwide list, and no majority bonuses, so providing a pure proportional representative system and yet which also provides a big party, able to govern the country.

To do this we shall present an alternative way of voting, able to produce in each election multiple results (multiple assignation of the parliamentary seats), each a representative one. In other words, the voting system will not produce a single result, but a space of possible results, all equally representative. First, in the next section, we shall present the most majoritarian-like among those results. And then, in the following section, we shall study the general space of all the parliaments that are representative. 


\section{Ways to vote}

\subsection{Assignment of the ballot papers}

We have reached now one of the key points of this paper.

In most of the usual electoral systems each voter is allowed to express a preference for a single party (or to abstain from voting).

In the voting system we are introducing we allow each voter to express their preference not for a single party, but for multiple parties. In fact, they should vote for all the parties that they feel can represent them, without expressing a preference among those choices. In this, the voting ballot paper will be similar to the one used for (the single-winner method) approval voting. ${ }^{3}$

What is important is that expressing multiple options will not be interpreted as splitting the votes between all those parties, nor for voting for all of them at once. Instead the ballot paper will still be assigned to one and only one of the parties chosen by the voter. To exactly which party, among those he has chosen, will not be controlled by the voter, but by other factors.

It is as if the voter offered a ballot paper with multiple possibilities while saying: "any of those parties can represent me". At this point each ballot paper will have to be assigned to a single party, and the parliament obtained by associating those ballot papers to those parties will be appointed. It should be noted that this produces multiple possible parliaments, depending on how the ballot papers are assigned. But all possible parliaments thus assigned are proportionally representative.

In other words, we can associate to each party a set of ballot papers (i.e., of people that have voted only for it, or together with other parties), and the number of representatives will be proportional to the number of assigned ballot papers. So we can associate to each elected representative in the parliament a block of roughly equal size of people who have voted for that representative's party.

Of course, if someone voted for only one party his vote can only be assigned to that party. If every person voted for only one party, the voting system will be equivalent to a purely proportional system. At the other end of the spectrum, if everybody voted for every possible party, then any parliament would be representative.

We shall now see a way to assign the votes in such a way to assign to a party the widest possible majority that is representative of people's votes, so making this party more effective in its possibility to govern. As such, this is the "most majoritarian" system among the proportionally representative ones.

\subsection{A special case: a majoritarian representative system}

Once people have voted, we need to assign each ballot paper to one and only one party. Let us suppose we have $p$ parties and $v$ voters.

\footnotetext{
3 There are actually two ways of using approval voting to elect a set of winners: either as a multiwinner rule (where voters vote for names), or as party-list election (where voters vote for parties). Approval voting seems to have been used much more in the first context, which is reviewed in Kilgour (2010).
} 
- We shall assign to the party that has received the greatest number of votes - call it party $p_{1}$-all the ballot papers from the people who voted for that party, ignoring thus all other preferences they might have chosen.

- We are then left with a smaller set of ballot papers, $v_{2}$, to assign, consisting of all the ballot papers in which party $p_{1}$ does not appear. Again, we will count all the votes in $v_{2}$, and again choose the party $p_{2}$ with the most votes, to assign to it all the ballot papers (in $v_{2}$ ) voting for it.

- This leaves a smaller set of ballot papers $v_{3}$ to be assigned among the remaining $p-2$ parties, and we iterate the above procedure.

- Once all the ballot papers have been assigned, the seats are assigned following a purely proportional system. ${ }^{4}$

Let us now look at some consequences of this way of assigning the votes:

1. First of all, each party will receive a number of ballot papers in the range between the number of people that voted only for it, and the total number of votes it has received.

2. Second, when two parties are aiming at representing a similar part of the electorate, the bigger one will absorb all the votes of the people that voted for both:

(a) So, in the case of two "clones", 5 only one, the bigger, will survive, leaving the other one with very few or no ballot papers at all.

(b) On the other hand, two parties that are supported by two disjoint sets of people will not damage each other and will eventually coexist in the parliament.

This should be seen as one of the features of the system, since it identifies "redundant" parties and damages or even eliminates them.

Also, we can see this voting method as producing an instability, where a small difference among the parties can produce a big change in the result. But this big change is bounded by the resulting parliament having to still be proportionally representative. Thus, looking at the results, we can always track each party to the set of voters that were willing to be represented by it.

This system can be compared to the Chamberlin-Courant system (see Chamberlin and Courant 1983) applied to approval votes (i.e., for the case where each voter specifies whom he or she approves), and in particular to the greedy approximation algorithm for the Chamberlin-Courant rule due to Lu and Boutilier (2011) for the case

\footnotetext{
4 Note that this is where we stop in the description and analysis of our system, that is, with the selection, out of each ballot, of a specific party-list among those selected by the voter. To go from this to an actual parliament, whose number of seats is specified, one of the existing purely proportional apportionment rules must be used, for instance one of the variants of the largest remainder method. The question of apportionment is a topical research area within multiwinner voting systems (see for instance Brill et al. (2017), which shows how approval-based multiwinner election rules can be interpreted as methods of apportionment).

5 The notion of "clones" in voting theory was introduced by Tideman Tideman (1987), in the setting of ranking-based voting systems, while it is "problematic" to define them in the context of approval voting or an approval-like system like the present one. The working definition we propose here is that a set of parties is a set of clones if no voters votes for just some of them and some party out of them. More formally, the subset $C$ of parties is a set of clones if whenever a voter votes for $c \in C$ and for $d \notin C$, they vote for all the elements of $C$. This definition allows for more flexibility than the direct extension of the definition, as of a set in which either all or none of the "clone" parties appear on any ballot.
} 
where we have party-lists of candidates. These procedures become the same as the one presented here if each party list admitted to the parliament is entitled to have a single representative: then the Lu-Boutilier greedy algorithm (or its adaptation to approval voting) starts by selecting the candidate approved most often, elects him, then cancels all voters who voted for him, and then iterates. Instead in our method, at each step, a number of representatives, which is generally larger than 1 , is elected.

Indeed, the result obtained electing a committee (with at most one representative per party) or a parliament are very different. Suppose that $52 \%$ of the people agree on a specific candidate/party. If we are electing a committee we would give to this person one seat, and thus a minoritarian position, while if we are electing a parliament (as in our system), we would give to this party $52 \%$ of the seats, so enough to govern alone. Both systems permit representativity, but the Chamberlin-Courant system does not ensure governability. It should be noted that in a parliament/committee that uses unanimous consensus to govern that difference becomes irrelevant.

\subsection{Other implementations}

The system described in the previous section is just one of the possible applications of the more general framework presented here.

In general, a rule must be explicitly presented to decide the way in which the ballot papers are assigned to the different parties. This can be an external rule whose actual outcome is decided either after the voting (as in the particular system of the previous section, which assigns seats to parties according to the order given by the decreasing number of votes received) or beforehand (fixing before the voting the order in which ballot papers will be assigned).

One way to produce a representative parliament from a set of ballot papers is to start with a list of parties and then to assign the seats following the order. First assign all the seats that can be assigned to the first party in the list, then among the remaining ballot papers assign the seats to the second party in the list, and so on. If we have $n$ possible parties, we would have $n$ ! possible combinations. As we shall see in next section, if we consider the convex space of all possible representative parliaments, those $n$ ! solutions represent the vertices of this space.

The interior of this space will be represented by parliaments where equal ballot papers, i.e. ballot papers of people that voted for the same parties, are not all assigned to the same one party. And generally these will be more balanced parliaments, with the size of the parties more similar, but also where no party dominates the parliament.

Another particular case is that in which an external authority fixes this order. For instance, it might be a president or monarch wishing to form a cabinet supported by certain parties. This authority begins by assigning ballot papers to some parties to give them the widest majority within the limits given by a proportionally representative democracy. As such the system would produce a form of check and balance between the electorate's wishes on the one side, and another state power's.

In general, in a more formal vein: given a set $P$ of $p$ party-lists, the ballot expressed by voter $i$ is a (non-empty) subset $u_{i}$ of $P$. So the input of the election is a $v$-tuple $u=\left\langle u_{1}, u_{2}, \ldots, u_{v}\right\rangle$, where $v$ is the number of voters. Define a classical profile 
$w=\left\langle w_{1}, w_{2}, \ldots, w_{v}\right\rangle$ (where $w_{i} \in P$ for all $i$, that is, each voter votes for exactly one party) to be compatible with the input $u$ if, for each $i, w_{i}$ is in $u_{i}$. In other words, a profile $w$ is compatible with $u$ if it is an element of the Cartesian product $\prod_{i} u_{i}$.

A rule is here any procedure given in advance that determines how, given a $v$-tuple $u$, a particular classical profile compatible with $u$ is to be chosen. Note that, a priori, a rule can be algorithmic - as in the examples above based on a fixed ordering of the parties, possibly with a random element ${ }^{6}$ - or non-algorithmic, entailing for instance the involvement of an external figure (as in the above example about the president or monarch).

Such generalised scenarios are those in which the difference between the system given here and other existing systems is particularly evident, especially the fact that here the ballot papers express an OR-choice, not an AND-choice. In an approval-voting spirit, voters selecting more than one party are delegating any of them indifferently. So, if a significant number of voters chooses more than one party, majority coalitions compatible with a given set of ballot papers and the representativity requirements may differ dramatically and anyone able to choose the order in which the parties should be assigned the ballot papers would have an enormous power over the produced parliament, but always within the limits that the result would always have to be representative of the voters ballot papers. And the choice over which party is able to govern with an absolute majority would generally be limited to one or two similar parties.

In principle, we might consider each ballot paper individually and decide to which list it should be assigned. In practice, it would be unfeasible, but as we shall see in the next section, given a ballot set, we may identify a "space" of possible parliaments that are compatible with that set, so that any point of this space is a representative parliament.

\subsection{Some properties of the system}

The voting system we have been describing, in his majoritarian representative form, satisfies several of the usual criteria for voting system. (Note that the following criteria are often given for ranked voting systems; when necessary, ours may be considered a ranking system by ranking all the selected party-lists above all the excluded ones, like in approval voting.)

Recall that the monotonicity criterion holds, in our terms, if it is never the case that adding a party to a voter's ballot would harm that party (that is, lower the number of ballots assigned to it at the end), or vice versa. In other words, let, as above, $P$ be the set of the party-lists and $u \subset P$ be the earlier ballot of the voter, and let $a \in P \backslash u$ be the new party-list added to the voter's ballot. The criterion holds if the total number of ballots assigned to $a$ does not decrease when that particular voter's choice changes from $u$ to $u \cup\{a\}$. That it holds for our system is easily seen by a sort of induction. If $a$ was the most voted party to begin with, in the new situation it obtains one more

\footnotetext{
${ }^{6}$ Even "choose a random element from each $u_{i}$ " is a rule yielding a compatible profile. So, in Machover (2012) words, the present system may admit both a "deterministic processing" or a "lottery processing", even though the majoritarian representative system most of this paper is devoted to clearly involves a deterministic processing.
} 
net ballot. Inductively, once we reach $a$ after having assigned the ballots to the parties above it, either the modified ballot has been excluded in one of the previous steps, so nothing changes for the party, or, as in the first case, it yields it one extra net ballot.

The participation criterion needs a slight rephrasing in this context (again, because we are not dealing here with a total ranking of some or all of the party-lists). We shall say that it holds in the present context if adding one voter and their ballot does not harm all of their preferred parties. More formally: let again $P$ be the set of the party-lists and $u \subseteq P$ be the ballot of the extra voter, and let $a \in u \subseteq P$ be the element of $u$ that, before adding the new ballot, received the most ballots. We say that the participation criterion holds if, after adding the new ballot, the number of ballots assigned to $a$ does not decrease. And this, by an induction argument analogous to the above one, is easily see to hold.

Our majoritarian representative voting system is consistent too. Recall that a voting system is said to be consistent if, however we divide the electorate into two or more parts such that each part obtains the same result (in this case, the same proportion of seats), then a voting involving the entire electorate also gives that same result. Notice that there is the strong hypothesis that the outcome of the voting (that is, the result of applying the social choice function) is the same for each of the disjoint subsets.

For our majoritarian representative system this holds indeed, since by hypothesis the party-lists have obtained the same proportions of votes in each subset, so summing them up, the total yields again the same proportions. This can be seen by induction: by hypothesis, in each of the subsets the party-list that received the most ballots is the same one; so we can count its results, remove the ballots including it and find ourselves in an analogue situation with one less list.

On the other hand, this property is not in practice very interesting in our setting, since its hypothesis would require that each subset of the set of party-lists has received the same proportion of votes in each subdivision of the electorate. Considering that if we have $p$ parties, the number of subsets that need to have the same proportion of voters would be $2^{p}-1$, this is a very strong requirement to make.

What some of the systems we present here lack is a more general kind of consistency: in our majoritarian representative system it is possible to split the electorate in such a way that applying the system to each part and then combining the results we obtain a global result different from the one obtained applying the system to the whole electorate. Here we do not assume anymore by hypothesis that the results are equal on all subsets. Indeed, the party that has received the greatest number of votes may-and in general will — be different in different districts or different sections of the electorate, hence yielding a different global result.

Thus, our system, if applied to multiple constituencies rather than nationwide, would be susceptible to gerrymandering-like phenomena. Note that the latter are partly due to the effect of "wasted votes", but in the system that we are describing here there are no actual wasted votes (apart from small effects such as the remainders in the proportional allotment). What is wasted, in a sense, is information, that is, the further lists included by each voter in their ballot paper besides the one actually selected by the system. 


\section{A theoretical result: the space of representative parliaments is convex}

Having considered some special cases of the system we are describing (assigning as many ballot papers as possible to the most voted party, having an external authority in charge of assigning them etc.), we intend now to study the structure of all the possible solutions (that is, possible parliaments) for a given electoral result. In other words, which parliaments are actually representative?

Again, let's assume we have $p$ parties and $v$ voters. We here consider that each voter voted for at least one party and no voter cancelled their ballot paper. We can always safely bring ourselves into that situation. The space of all possible parliaments is given by the space of all the $p$-tuples $s=\left\langle s_{1}, s_{2}, \ldots, s_{p}\right\rangle$ that describe how many votes are assigned to each party; so, $0 \leq s_{i} \leq v$. The sum of the $s_{i}$ must be $v$ (because each vote is counted exactly 1 time). As such, the total space of the possible parliamentary configurations is a standard simplex, the convex hull of the tuples corresponding to parliaments where a single party has all the seats; geometrically, this is a particular polytope (a generalisation of the notion of 2-dimensional polygons and 3-dimensional polyhedrons).

Let us call this simplex, the space of all possible parliaments (before divisions and remainders), $S$.

Not all those configurations are representative. So $R$ will be the subspace of $S$ given by all the configurations that are representative for a given voting result.

Let us now see all the possible ways people can vote. Each person can choose a set of parties, except for the empty set. So each person has $2^{p}-1$ possible choices. Each of the possible poll results can then be represented by a $v$-tuple $u=\left\langle u_{1}, u_{2}, \ldots, u_{v}\right\rangle$ with $u_{i}$ the way voter $i$ voted, i.e. one of $2^{p}-1$ possible choices.

Now, given a particular voting result $u$, we are interested in finding out the shape of $R$.

For each voter we need to choose one of the parties chosen by that voter, that is, we have to choose to which party assign that voter's ballot paper. This means that, if participant $i$ voted the set $u_{i}$, we are interested in the Cartesian product of all the sets $u_{i}$, for all $i$. Let us call this $C$.

An example will clarify this. Suppose we have two voters $\{1,2\}$ and three parties $\{a, b, c\}$. Voter 1 voted for $a$ and $b\left(u_{1}=\{a, b\}\right)$, while voter 2 voted for $b$ and $c\left(u_{2}=\{b, c\}\right)$. We are interested in $C=u_{1} \times u_{2}=\{a, b\} \times\{b, c\}=$ $\{(a, b),(a, c),(b, b),(b, c)\}$ and each of those elements will represents an acceptable result.

We are now going to prove that the subspace $R$ is convex, that is, for any two points $x, y$ in $R$ (i.e., for any two ballot assignations that are compatible with a given voting result) any other point on the line segment having $x$ and $y$ as endpoints belongs to $R$ (i.e., any parliament in which every party has a number of seats between those it had in $x$ and those in $y$ is itself compatible).

Notice first that, even though the points we are interested in have integer coordinates (the numbers of seats assigned to the different parties), the theoretical framework of simplexes and polytopes is relevant, since we may consider the intersection between these geometrical structures and the set of points with integer coordinates. 
Consider now, for a given subset $A$ of parties, the set of all voters who chose exactly the set $A$ and denote the number of those voters by $n$. All the $p$-tuples describing the possible assignations of their ballot papers form, again, a simplex (of dimension $|A|-1$ and edge length $n$ ). Its extremal points, or vertices, are the $p$-tuples with one coordinate equal to $n$ while the other ones are all zero, corresponding to assigning all $n$ votes to the same party.

To pass from these simplexes, one for each subset of parties, to the more complex structures encompassing all possible ballot papers, we have to consider all possible sums of elements of the simplexes, one from each simplex. This is called the Minkowski sum of those polytopes, and it is known that the Minkowski sum of polytopes is also a polytope, and precisely the convex hull of the Minkowski sum of the extremal points of the summands, which were themselves convex, by being simplexes. (For a good survey on definitions and results about polytopes and operations on them, see Weibel 2007.)

Thus, we have shown that the set of all parliaments obtainable from a given voting result is convex, and its vertices, or extremal points, correspond to the parliaments obtained "by lists", that is, as described in Sect. 3.3, by fixing in all possible ways an ordering of the parties, and then proceeding to assign the ballot papers to the parties in that order. Indeed, these are exactly the ways to go "as far as possible" in each of the directions represented by the parties.

So we can start, for instance, by taking three possible lists (orderings of the parties) and obtain three possible parliaments: a triangle on the simplex. For each possible parliament inside the triangle, we are sure there exists a possible way of assigning the ballot papers that leads to this parliament.

Discovering that the space of possible parties is convex is an important result. Thanks to it, we can now pick the set of all possible ordering of the lists, and obtain the extremal points of the polytope. Then we can pick any point inside the polytope, and be sure that there is a solution, a way of assigning the ballots, that will lead to that result. The solution might look arbitrary, and even capricious, but it would still be representative (something that cannot be said for all present majoritarian systems).

This opens up the possibility of inserting additional requirements on the kind of parliament that can be elected. We can, for instance, decide that the first party should not control more than a certain percentage of the parliament.

In the previous section we have suggested that a form of check and balance between various actors of the State might lead to an external authority deciding in what order parties should be selected. The convexity of the polytope leads us to potentially extend this power permitting to an external power not just to assign an order among the parties, but to arbitrarily select any one of the parliaments inside the polytope. And, as long as the produced parliament is inside the polytope, the result would be representative.

And here we finally see the importance of this way of voting. If we ask people to rank all the parties from the one they like the most to the one they like the least, or even just pick a single party, most voting systems aim at giving as result one and only one final parliament, which will be seen as the "only" representative parliament. Any straying from it would be seen as a betrayal of the electors.

On the other side, when we ask them to list multiple parties with the agreement that any one of those parties might be chosen, this opens up the space of possible 
solutions. Now suddenly there is not one single proportionally representative parliament, but a whole polytope. It can then be additionally dissected by providing further requirements, reaching a solution that satisfies a wider range of needs (for instance, a parliament that is both representative proportional and majoritarian). It should be noted that while this might be seen as unfair respect to the voters, the possibility for them to vote for a single party makes sure that anyone who is unhappy with this possibility can just vote for one party and will have his vote been treated as a normal plurality vote in a normal proportional representation system.

\section{Testing the system}

We tested the system both through a simulation of an election and by asking two classes of university students, in total 260 students, to vote. We analysed the results by comparing what would have happened if we processed the votes according to the purely proportional system, the then current Italian system, and our majoritarian representative system.

\subsection{Simulating an election}

We tested the system by simulating multiple elections. First we fixed a number of parties and assigned to each party a random position in a 2 -dimensional square $[0,1] \times$ $[0,1]$. This is a purely abstract representation of a possible "space of ideologies", and as such its dimension might well be different from two (but recall that some authors have actually given descriptions of concrete political positions in term of two axes, as described for instance in Lester 1996).

We then randomly placed, on the same space, 5000 voters. At this point we could define the distance $d$ between each voter and each party as the Euclidean distance between the voter position and the party position. Thus, we defined the probability for a voter to vote for a party as $p=(1-d)^{k}$, for $k$ a fixed parameter.

We then randomly determined each election result and extracted the number of elected representatives for each party. We then ran the election 100 times, randomly placing the parties and the voters each time. Then, we plotted the average size of the parties, ordered by the biggest to the smallest. The results can be seen in Fig. 1.

We tried this for several values of $k$, and several numbers of parties and of voters. Of course we did not know what value of $k$ was a better fit for reality, and future work will try to establish this.

What came out was an extremely consistent result. The party sizes, ordered by number of elected representatives, tended to decrease exponentially, with an exponent that did not depend on the number of parties, nor the number of voters, but did depend on the $k$. For $k=\sqrt{2}$, the first party had an average size of $49.9 \% \pm 1.4 \%$. That particular value of $k$ was chosen, pending further work, since it seems to approximate the empirical results described in next section. 

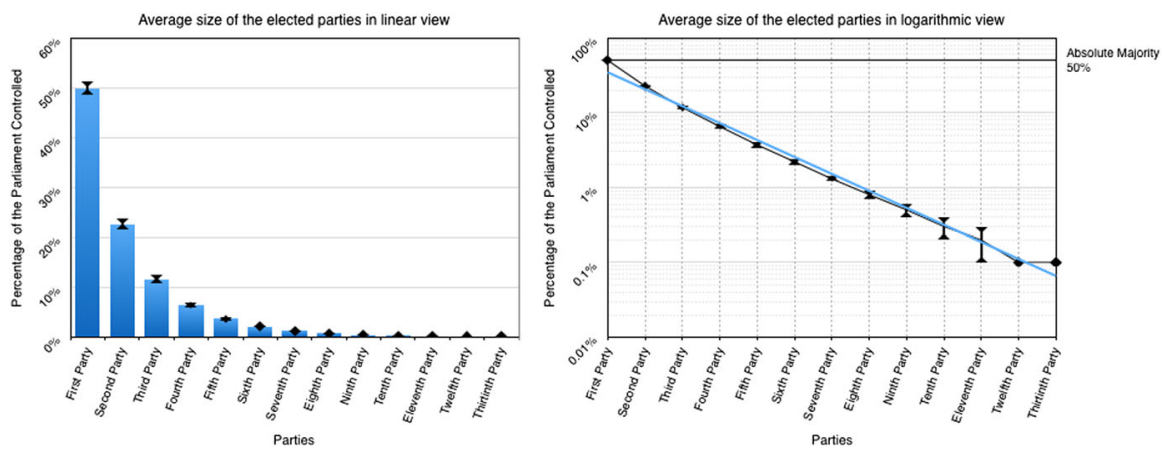

Fig. 1 Running the simulation 100 times, with 5000 voters voting 20 parties, and $k=1.424$

\subsection{Case report: asking 260 students to vote using this system}

We asked two classes of undergraduates to anonymously vote for the nine main parties in the present Italian political arena. The parties we presented were Partito Democratico (PD), Movimento 5 Stelle (M5S), Forza Italia (FI), Sinistra Ecologia e Libertà (SEL), Nuovo Centro Destra (NCD), Fratelli d'Italia, Scelta Civica, Unione di Centro (UDC), Lega Nord (Lega). Each student had to complete four different forms:

form 1: students voted for all the parties any one of which they would send to the parliament to represent them;

form 2: students voted for a single party they would send to the parliament to represent them;

form 3: students ordered the parties from the one they liked most to the one they liked least;

form 4: students evaluated each party on a 5-option system (terrible, scarce, sufficient, good, excellent).

The first class of students was from the faculty of sociology and consisted of 145 students. The second class was from the faculty of economy and consisted of 115 students. The first thing that should be noted was how inconsistent the votes were. Several students did not vote (in the first form) for the parties they liked most (as listed in the third form).

We analysed the results for three groups of people, only the sociologists (group 1), only the economists (group 2), both the sociologists and the economists (group 3).

We then studied the parliament that would be generated by using a purely proportional system, the Italian electoral system at the time (the so-called Italicum), and the majoritarian representative electoral system presented here. The Italicum is a winnertake-all majoritarian system with a threshold of 3\%, and such that if the relative majority party has more than $40 \%$ of the votes it will gain $54 \%$ of the seats, while if the relative majority party has less than $40 \%$ a second election will be held among the two top parties, with the winning party getting $54 \%$ of the seats. The remaining seats are awarded using a proportional system. Notice that in the version of the Italicum we used in the testing there was a single constituency, while the Italicum uses 100 constituencies each electing 3-9 members of parliament. 

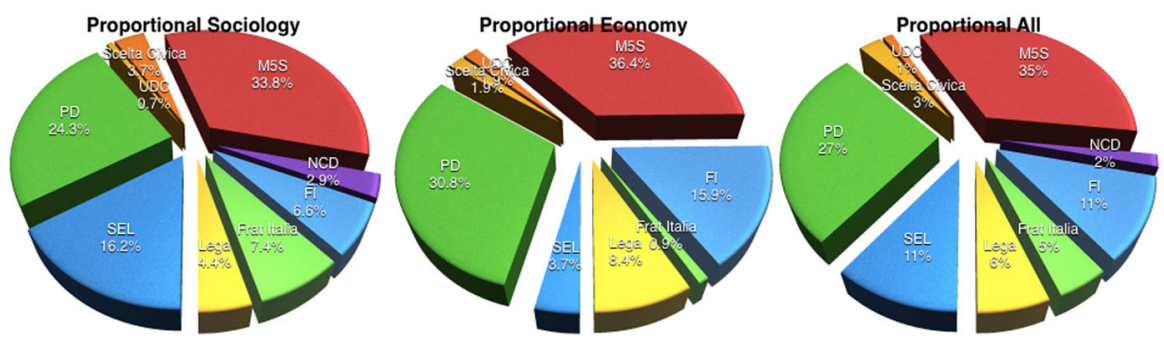

Fig. 2 Winning parliaments using a purely proportional system
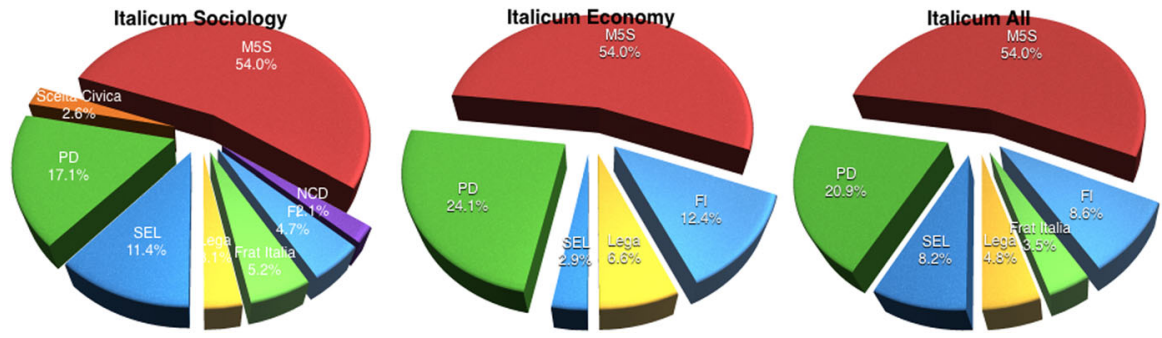

Fig. 3 Winning parliaments using the "Italicum" system

So let's see first the winning parliament for the three groups of people-the sociologists, the economists and all together-when we use a purely proportional system (Fig. 2).

As it could be expected, the result has several parties, with three major parties, but no party able to govern alone. A similar result happened (albeit not using a purely proportional representation) during the 2013 elections, with three very different parties freezing the political situation. Now let us look at the situation using the Italicum (Fig. 3).

In no group there was a party that was able to collect $40 \%$ of the electorate. So we had to simulate a runoff voting between the two top parties, PD and M5S. For this we used the third form, where the students could indicate in what order they favoured the parties. In all cases the Movimento 5 Stelle won. So the result showed a clear winner in the Movimento 5 Stelle, to which $54 \%$ of the parliament was given. The rest of the parliament was a bit different between the various groups of people, possibly reflecting the ideological differences between the average person studying economy or studying sociology.

Finally we applied our majoritarian representative system to the votes. And the surprising result was that it ended up being very similar to the Italicum (Fig. 4).

Again, in all cases the Movimento 5 Stelle won. Also the percentage was very similar to the one assigned through the Italicum $(52.9 \%, 54.1 \%, 53.5 \%$ versus $54 \%)$.

While there is no reason why the results should be similar to the Italicum, the simulation showed that the size of the first party tended to be always the same, and the two experiments we carried out showed similar results. So if having a first party of $54 \%$ is the optimal percentage to govern, it is a lucky coincidence that this system offers a similar result. But, if this reproduces the behaviour in the simulation, it might 

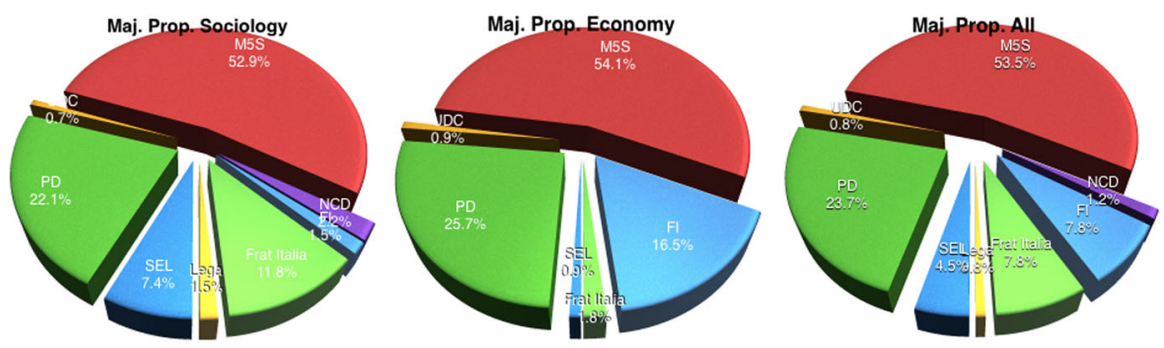

Fig. 4 Winning parliaments using the system presented here

be a consistent result and other experiments done with other parties and other voters might also produce a first party with a popularity of around $53 \%$.

Of course the difference is that it is theoretically possible, in the majoritarian representative system, to connect each voter to the candidate they helped elect, like in the proportional representation and unlike in the Italicum. Moreover, it is interesting which parties disappeared in the majoritarian representative system. By the way the system is designed, each party will always receive a number of ballot papers between a minimum of just the ballot papers of voters that only voted for that party, and a maximum of all the ballot papers of the voters that also voted for that party. So, when a party disappears, it means that all the voters that voted for it were also happy with other parties. This was the case with Scelta Civica, in all three groups, and Lega Nord and NCD among the economists.

The case of Lega Nord was especially revealing, since it had 19 votes out of 109 valid ballot papers: thus, $17.4 \%$ of the voters were willing to also be represented by it, but all of them were also happy to see another party represent them. After Movimento 5 Stelle got its votes the number decreased to 14, after the PD it went to 10, and after Forza Italia to just 1, which was lost when Fratelli d'Italia received its ballot papers. This example shows very well how the system works: parties that are similar take away votes to each other when one is selected, while parties that are different are barely changed. This is very important in the case of cloning. If a party splits into two clones, only one will generally survive, and it will end up with about the original size of the original party. The second, weaker party will only remain (if at all) to represent the people that would not feel represented by the first party.

The complete table of how the votes were assigned in the sociology class clarifies these points even more. Ordering the parties by the number of votes received, we get: M5S, PD, SEL, Fratelli d'Italia, Forza Italia, Lega Nord, Scelta Civica, NCD, UDC. It did not change much after the M5S received its votes. However, after the PD received its votes, the order changed radically and SEL moved from 25 ballot papers (3rd position) to 12 ballot papers (4th position) while Fratelli d'Italia moved from 18 ballot papers to 16 ballot papers (3rd position). PD and SEL are in fact quite close in terms of electorate, the former being a centre-left party and the latter more decidedly left-wing. Instead Fratelli d'Italia, being on the extreme right, had only two ballot papers in common with the PD. In this way the system, even after assigning ballot papers to the first party, continued assigning a bigger stake to the second and further 
parties (if the votes received entitle them to it). So we do not get only a large majority party, but also an opposition made up of few, bigger, parties.

\begin{tabular}{llrlllllr}
\hline PD & M5S & FI & SEL & NCD & Fr. Italia & Sc. Civ. & UDC & Lega \\
\hline 58 & $\mathbf{7 2}$ & 20 & 37 & 6 & 21 & 9 & 3 & 13 \\
$\mathbf{3 0}$ & & 11 & 25 & 6 & 18 & 5 & 2 & 6 \\
& & 8 & 12 & 4 & $\mathbf{1 6}$ & 4 & 1 & 4 \\
& 2 & $\mathbf{1 0}$ & 3 & & 4 & 1 & 2 \\
& 2 & & $\mathbf{3}$ & & 1 & 1 & 2 \\
& & $\mathbf{2}$ & & & & 1 & 1 & $\mathbf{2}$ \\
$\mathbf{3 0}$ & $\mathbf{7 2}$ & $\mathbf{2}$ & $\mathbf{1 0}$ & $\mathbf{3}$ & $\mathbf{1 6}$ & $\mathbf{0}$ & 1 & $\mathbf{1}$ \\
\hline
\end{tabular}

Another thing that should be considered is how should ties be resolved. First of all, in real elections ties are very rare. We did face a tie, and in "Appendix" we discuss at length how it was evaluated, and the four possible alternative parliaments that could be reached. In general, recalling what we wrote in Sect. 3.3, the simplest way to resolve a tie is to let an external authority decide how to proceed.

\section{Adapting the system to external constraints}

So far, we have discussed the election of a single house of representatives, where we tried to maximise the size of few parties, and voters had no way to express a preference over a particular politician to elect.

The system can easily be modified to let people express a preference for one politician or another. This can be done by adding a space in the ballot paper next to each party, where the voter can express their preference by adding the name of a politician. Then the preference is only considered if that ballot paper is assigned to that specific party. In this way, parties that are elected by a wide majority will have the politicians selected by that majority, while parties that are elected by few people that only voted for them (as the other ballot papers were assigned elsewhere) will have their representative chosen by those few people.

Another problem has to do with how a parliament made up of two houses is elected, especially since the government might need to be supported by a majority on both houses. In this case it is important that the parties are assigned seats in the same order, especially for the first party. To do this, instead of simply choosing the party that has the maximum number of votes, we need to assign to each party a number which will be the minimum among the number of votes it received in both houses of the parliament, and then pick the party that has the maximum among those numbers. So if we have five parties, $A, B, C, D, E$, and the number of votes are $A_{l}, A_{s}$ (the votes for $A$ for the lower house and for the Senate, say), $B_{l}, B_{s}$ and so on, then we need to assign $A_{m}=\min \left(A_{l}, A_{s}\right), B_{m}=\min \left(B_{l}, B_{S}\right)$ etc. And then pick the party that has the highest number among $A_{m}, B_{m}, C_{m}, D_{m}$, and $E_{m}$. This will be sure to elect the party with the biggest possible representation in both houses. Once the first party 
is chosen, the procedure is repeated for the second party using the remaining ballot papers, and so on.

\section{Conclusions}

We presented a novel electoral system. This system combines two requirements that were previously considered mutually exclusive: producing a parliament that is proportional to what the voters want and producing a parliament with one large party able to govern the nation.

\begin{tabular}{llll}
\hline & & \multicolumn{2}{c}{ Does it produce one big party able to govern? } \\
\cline { 3 - 4 } & & No & Yes \\
\hline Is it proportional? & No & & Italicum and majoritarian systems \\
& Yes & Proportional systems & Majoritarian representative system \\
\hline
\end{tabular}

The system does not always produces a winning party that reaches the absolute majority of the parliament, but just the biggest possible parliamentary presence that would still be proportionally representative. We tested the system on 260 undergraduate students and on a computer simulation. The results with the students appeared to be extremely similar to the result of the Italicum (the Italian majority-bonus system), while retaining the proportional representative quality. On the other hand, the simulation allowed us to gather more data on the relative size of the parliaments that appear, as well as to find out that the sizes of the elected parties tend to decrease exponentially with an exponent that does not depend on the number of parties or the size of the electorate.

All this is possible by letting voters chose multiple parties, and then letting the algorithm choose among those parties which one to assign the ballot paper to. While we presented a specific algorithm to assign the ballot papers, many more are possible, and as long as each ballot paper is assigned to one of the parties voted, all produce a representative system. We proved that the space of all possible representative systems is in fact convex and (if $n$ is the number of parties) its limits are given by the $n$ ! "extreme" possible ways to assign the ballot papers.

One might be struck by the present system as being an "unfair" one, since it may lead almost to the disappearance of parties that have a large following, that is, are voted by many people (albeit together with other parties). But the point is that this system is "fair" towards voters, a larger number of which gets to be represented in any final assignation of the ballot paper, rather that towards the parties, which are just a tool to categorise the voters' preferences.

Another fear that this system might raise is that some party might be so popular that next to everybody votes for it, the result being a party with $90 \%$ of the parliament. This is actually a very unrealistic scenario. Still, it can easily be countered by placing external limits, and decide that no party will receive ballot papers that will push it over a threshold (say 55\%) unless the voters voted only for that party. Then we would start 
to assign the votes starting with the ballot papers that only voted for that party, and stop once we reach the threshold. A randomly chosen subset of the remaining votes would be assigned to the other parties.

Of course, there remain many questions still open. In particular, it is not clear how voters would react to the idea that they can vote multiple parties but only one will be used and they have no control over which one. Surely some people would react by voting just a single party, but others would welcome the possibility to support the strongest party among the ones they agree with. Also, each voting system does not exist in a vacuum; parties react to it by slowly changing their ideology: moving more toward the centre, or more toward an extreme, depending on what is more favourable, splitting up, merging or building alliances. All this creates a dynamic feedback loop between the voters and the parties whose results are very difficult to predict. Future works will aim to address some of those questions by trying to develop further the simulation, and measure what values of the parameter $k$ best approach the willingness of voters to vote for certain parties.

Acknowledgements We thank Jérôme Lang for the intellectual support. We also thank Mara Maretti, Lara Fontanella, Luigi Ippoliti, Piotr Skowron and the anonymous reviewers, for the interesting discussions, the support in gathering the data and the useful remarks and pointers to literature.

Open Access This article is distributed under the terms of the Creative Commons Attribution 4.0 International License (http://creativecommons.org/licenses/by/4.0/), which permits unrestricted use, distribution, and reproduction in any medium, provided you give appropriate credit to the original author(s) and the source, provide a link to the Creative Commons license, and indicate if changes were made.

\section{Appendix: Handling a tie}

A tie can have very different results depending on how it is solved. Such a situation happened when we considered cumulatively all the ballot papers obtained from the students. The first party to win seats was the Movimento 5 Stelle, then the PD, but then there was a tie. Both Forza Italia and Fratelli d'Italia had 26 ballot papers left, while the total sum of ballot papers available between Forza Italia and Fratelli d'Italia was not 52 but 38, since 14 people voted for both Forza Italia and Fratelli d'Italia.

\begin{tabular}{lllllllll}
\hline PD & M5S & FI & SEL & NCD & Fr. Italia & Sc. Civ. & UDC & Lega \\
\hline 107 & $\mathbf{1 3 1}$ & 55 & 60 & 13 & 36 & 15 & 13 & 32 \\
$\mathbf{5 8}$ & & 31 & 35 & 10 & 30 & 8 & 6 & 20 \\
& & $\mathbf{2 6}$ & 13 & 6 & $\mathbf{2 6}$ & 4 & 3 & 14 \\
\hline
\end{tabular}

How should this situation be solved? There are three natural ways in which this situation can be solved, and of course more creative ways are always possible. Each of those three ways has some limits. So rather then offering a solution we shall present all of them. In any case it is obvious that this kind of problems is extremely rare in real elections. 
The first possibility is to split the ballot papers equally among the two parties. This works perfectly if the two parties have no ballot papers in common. But it somehow defies the purpose of the voting system if there are several ballot papers in common. After all, if such a tie happened between two opposing big parties, none would win enough seats to govern. In any case the number of ballot papers to assign and split would be the total number of ballot papers that voted for both parties, not the sum of the number of ballot papers that voted for one or the other party. In our case the order in which parties would be assigned seats would be:

$$
\mathrm{M} 5 \mathrm{~S}>\mathrm{PD}>\mathrm{FI}=\text { Fratelli d'Italia }>\mathrm{SEL}>\mathrm{NCD}>\mathrm{UDC}=\text { Lega }
$$

The second option is that an external authority — say, the president of the nationwould decide which of the two parties should win in this case. And then we continue assigning vote as if that chosen party had naturally won. Note that this might mean that the other party might not be the next one to win the seats. For example in the case above, if after the M5S and the PD we assigned the seats to Fratelli d'Italia then Forza Italia would be the next party. So the order was:

$$
\text { M5S }>\text { PD }>\text { Fratelli d'Italia }>\text { FI }>\text { SEL }>\text { NCD }>\text { Lega }=\text { UDC }
$$

But if Forza Italia were given the precedence, then the order would have been

$$
\text { M5S }>\text { PD }>\text { FI }>\text { SEL }>\text { Fratelli d'Italia }>\text { NCD }>\text { Lega }=\text { UDC }
$$

since there were more voters in common between SEL and Fratelli d'Italia than between SEL and Forza Italia (which is interesting in itself, considering that SEL represents the extreme left, Fratelli d'Italia represents the extreme right, and Forza Italia represents a more moderate extreme right).

The final option is to skip temporarily either party and assign the seats to the next party in line, and then go back to the previous parties once the next party has broken the tie. In this case the order in which the parties are assigned would have been:

$$
\text { M5S }>\text { PD }>\text { Lega }>\text { Fratelli d'Italia }>\text { SEL }>\text { FI }>\text { NCD }>\text { UDC }
$$

All this leads to four, substantially different parliaments (Fig. 5), all of them representative. And all of them with one party able to form a cabinet, the Movimento 5 Stelle. So all four parliaments are potentially acceptable, but with enormous local differences, with the Lega moving between 5.7\% and $0.8 \%$ and Forza Italia varying between $10.6 \%$ and $3.3 \%$. Although in this case any of those solution is acceptable, leading to a majoritarian representative parliament, this is not always the case for all possible ties.

In fact, if the tie were for the first place, it is quite likely that any solution that did not privilege either of the two winning parties would lead to a potentially ungovernable situation. So, considering how rare such situations are, a reasonable solution would be to assign to an external authority (like the incumbent president) to act as a tie breaker, choosing what direction should the procedure follow; alternatively, it would 

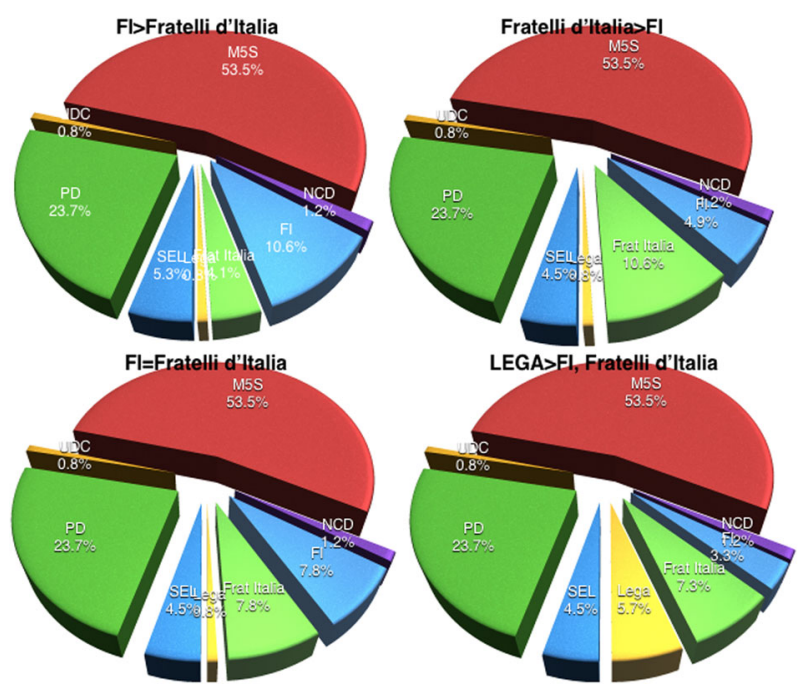

Fig. 5 Four possible ways to break ties

be possible to call for a second election just among the first two parties. Of, course, whatever strategy is chosen (showing the tie, breaking the ties using one of these methods, letting a third party benefit from it), it should be defined from before the voting started.

\section{References}

Arrow KJ (1950) A difficulty in the concept of social welfare. J Political Econ 58(4):328-346

Brill M, Laslier J-F, Skowron P (2017) Multiwinner approval rules as apportionment methods. In: Markovitch S, Singh SP (eds) Proceedings of the Thirty-First AAAI Conference on Artificial Intelligence (AAAI-17), AAAI Press, Palo Alto (CA), pp 414-420

Chamberlin JR, Courant PN (1983) Representative deliberations and representative decisions: proportional representation and the Borda rule. Am Political Sci Rev 77(3):718-733

Faliszewski P, Skowron P, Slinko A, Talmon N (2017) Multiwinner voting: a new challenge for social choice theory. In: Endriss U (ed) Trends in computational social choice, AI Access Foundation, chapter 2, pp $27-47$

Fesnic F (2008) Proportional representation. In: Warren KF (ed) Encyclopedia of U.S. campaigns, elections, and electoral behavior. SAGE Publications, Thousand Oaks, pp 677-679

Kilgour M (2010) Approval balloting for multi-winner elections. In: Laslier J-F, Sanver MR (eds) Handbook on approval voting. Studies in choice and welfare, Springer-Verlag, Berlin, pp 105-124

Lester JC (1996) The political compass (and why libertarianism is not right-wing). J Soc Philos 27(2):176186

Machover M (2012) The underlying assumptions of electoral systems. In: Felsenthal DS, Machover M (eds) Electoral systems: paradoxes, assumptions, and procedures. Studies in choice and welfare, vol 3. Springer, Berlin, pp 3-9

Lu T, Boutilier C (2011) Budgeted social choice: From consensus to personalized decision making. Proceedings of the Twenty-Second International Joint Conference on Artificial Intelligence, International Joint Conferences on Artificial Intelligence, vol 1. AAAI Press, Palo Alto (CA), pp 280-286

Reynolds A, Reilly B, Ellis A (eds) (2005) Electoral system design: the New International IDEA Handbook. International Institute for Democracy and Electoral Assistance, Stockholm 
Sartori G (1994) Comparative constitutional engineering. an inquiry into structures, incentives and outcomes. Macmillan, New York

Tideman TN (1987) Independence of clones as a criterion for voting rules. Soc Choice Welf 4:185-206

Weibel C (2007) Minkowski sum of polytopes: combinatorics and computation. École polytechnique fédérale de Lausanne, Thèse n. 3883. http://infoscience.epfl.ch/record/109334/files/EPFL_TH3883. pdf

Publisher's Note Springer Nature remains neutral with regard to jurisdictional claims in published maps and institutional affiliations. 